\title{
DISCRIMINATION INTEGRATED DEVELOPMENTAL SUPERVISION MODEL
}

Neffisatu Dambo*

\begin{abstract}
Counselor supervision is important for the development of future counselors and for client safety. Supervision is a process that provides monitoring, training, consultation, and feedback to help with counselors' development, skill, and competencies. Therefore, the purpose of this manuscript is to present the Discrimination Integrated Developmental Supervision Model (DIDSM), which is an integration of Bernard's (1997) Discrimination process model and Stoltenberg and Delworth's (1987) Integrated Developmental Model. The author will also discuss how the following DIDSM tenets are essential to counselor supervision: (a) the supervisory relationship, (b) modeling, (c) feedback, and (d) the awareness of self and others.
\end{abstract}

KEYWORDS: Counselor supervision; Discrimination integrated developmental model; Supervisory relationship.

The purpose of this manuscript is to provide information about the process, purpose, and practice of counselor supervision. This paper will introduce the Discrimination Integrated Developmental Model (DIDSM) as a supervision model, as well as discuss examples and practical implications implemented for supervisors in training. Counselor supervision is a process that provides a structure that promotes professional and ethical services to protect the welfare of the client (Bernard \& Goodyear, 2014; Falender \& Shafranske, 2004). Supervision is a hierarchical process where a trained senior member of a profession supervises a junior member of the profession. The senior member serves as a mentor and role model in order to facilitate the growth and professional development of

* Assistant Professor at Southern Illinois University (SIU). 
a junior member (Bernard \& Goodyear, 2014; Borders \& Brown, 2005; Murphy \& Kaffenerger, 2007). During the process of supervision, the supervisor provides support, encouragement, structure, monitoring, constructive feedback, evaluation, consultation, and guidance. This helps the supervisee develop skills, increase professionalism, psychological development, their identity as a counselor, practice compliance, and enhance competencies that can strengthen their delivery of counseling services (Borders \& Brown, 2005; Falender \& Shafranske, 2004; Lambie \& Sias, 2009; Ronnestad and Skovholt, 2003).

Supervisors' hierarchical leadership position requires them to intentionally structure supervision and operate from the role of consultant, counselor, and teacher. As a result of the supervisors' balanced roles and the delivery of roles at the appropriate times, students are likely to experience skill development, increased professionalism, psychological development, build professional identity, engage in ethical practice, and enhance counseling competencies (Borders \& Brown, 2005; Falender \& Shafranske, 2004; Gunn \& Pistole, 2012; Lambie \& Sias, 2009; Pope-Davis \& Coleman, 1997; Ronnestad and Skovholt, 2003; Worthen \& McNeil, 1996). Supervisees' become competent in their profession, have an attitude to grow and self-monitor, and demonstrate their ability to uphold professional, ethical, and legal standards (American Counseling Association, 2005; Baird, 2005; Lawton \& Feltham, 2000; Ronnestad \& Skovholt, 2003). The supervisees' ability to self-monitor, grow continuously, and demonstrate autonomy are primary goals of supervision. This is important because supervisees are unlikely to receive supervision after they complete internship and throughout their counseling career (Falender \& Shafranske, 2004, Morrisesette, 2001). Herlihy and Corey (2015) reported that only 13\% of professional school counselors receive clinical supervision.

Supervisors have the responsibility of adopting multiple roles that coexist with their position of power and professional obligation to maintain clear boundaries, while following ethical guidelines, and setting clear expectations for supervisees (Haber, 1996). Supervisors can be held accountable for the services rendered by their supervisees because ineffective 
supervision could lead to malpractice lawsuits and harm to clients' (Baird, 2005; Bernard \& Goodyear, 2014; Nugent, 1994; Pope-Davis \& Coleman, 1997; Wheeler, 1996). Therefore, counseling supervisors are expected to serve as ethical gatekeepers of the profession, as the client's welfare is priority above all other purposes and components of supervision when multicultural considerations and practices are in place (Estrada, 2005; Haber, 1996; Rapisarda \& Britton, 2007; Swank, Lambie, \& Witta, 2012; Wheeler, 1996). Due to the nature of supervision and the ethical and legal responsibilities of the supervisor, it is imperative that supervisees are trained (Corey, Corey, \& Callanan, 2011; McAuliffe \& Eriksen, 2002; Pearson, 2004).

Supervision is essential to counselor growth and development. Trained counselors are generally more knowledgeable, use a variety of techniques, are client focused, professional, ethical, confidential, and operate from a theoretical framework (Nugent, 1994; Young, 2005). For example, Ladany, Marotta, and Muse-Burke (2001) investigated counselor education and counselor psychology graduate students' $(N=100)$ and found that there was a significant $(\not<.05)$ relationship between counselor experience and counselor case conceptualization. Leach, Stoltenberg, Eichenfield, and McNeil (1997) examined graduate supervisees' ( $N=142$ ) (Level 1, $n=70$; level $2 n=72$ ) developmental level, which showed that level 2 supervisees who had prior experience and practice of working with clients' with difficult issues were more confident about working with clients' with challenging issues than level 1 supervisees $(p<.01)$. Leach, Stoltenberg, Eichenfield, and McNeil (1997) study also investigated the relationship between a supervisee's self-efficacy and level of experience. The results indicated a relationship between supervisees' level of experience and self-efficacy when working with clients who experienced abuse and depression. Supervisees' skill development and change resembles the parallel process in which their skills enhance the supervisees' ability to enhance the therapeutic process, thus client outcomes (Borders \& Brown, 2005; Young, 2001, Young 2005).

Supervision is essential to counselor development. Therefore, the author recommends the comprehensive DIDSM, which addresses the components deemed necessary to 
support the process of supervision (Stoltenberg \& McNeil, 2010). The following areas are important to consider during the supervision process: (a) supervisory match, (b) supervisee personality, (c) cognitive capacity, (d) developmental level, (e) theory, (f) culture, (g) learning style, and (h) wellness and mental health (Bernard \& Goodyear, 2014; Falender \& Shafranske, 2004).

\section{DIDSM's Supervisory Relationship}

The primary tenets of the DIDSM focus on the supervisory relationship, feedback, modeling, self-awareness, and cultural sensitivity. The supervisory relationship is more important than supervisory expertise, the supervisee developmental level, or supervisee experience (Bernard \& Goodyear, 2014; Worthen \& McNeil, 1996). Initiating rapport in the very beginning is best supervisory practice because it establishes the foundation needed for the supervision process to effectively proceed. (Lambie \& Sias, 2009; Lawton $\&$ Feltham, 2000). The relationship is the first stage of supervision and the therapeutic process; hence, the supervisory relationship serves as the foundation that drives the effectiveness of other DIDSM tenets. The DIDSM supervisory relationship promotes genuineness, empathy, and unconditional positive regard (Bernard \& Goodyear, 2014; Blocher, 1983; Studer, 2006; Stoltenberg \& McNeil, 2010; Ronnestad \& Skovholt, 2003; Young, 2001). A positive and professional supervisory relationship is important to the development of the supervisee and the supervisor's role as a mentor and role model (Blocher, 1983; Pearson, 2001; Lambie \& Sias, 2009). Modeling the supervisory relationship is reflective of isomorphism and the parallel process and can encourage supervisees to establish a strong therapeutic alliance with clients (Koltz, Odegard, Feit, Provost, \& Smith, 2012). The ability to establish a therapeutic alliance with clients promotes client wellness. This was supported by Norcross' (2012) meta-analysis $(N=201)$, which found a significant relationship between the therapeutic alliance and client outcomes. 


\section{Supervisory Relationship}

Supervisees who have positive relationships with their supervisors are more likely than supervisees with a poor relationship to disclose information, request assistance, feel relaxed, solicit feedback, and grow from supervision (Gunn \& Pistole, 2012; Lawton \& Feltham, 2000). The importance of the supervisory relationship is supported by Gunn and Pistole (2012). Gunn and Pistole (2012) found that supervisees from master and doctoral counseling programs $N=480$ (males, $n=80$; females, $n=393$ ) who perceived they had a strong relationship with their supervisor were also more likely to self-disclose. They also found that the supervisory relationship contributed to the supervisees' satisfaction of supervision and increased the likelihood of supervisees' to develop and build skills during the process of supervision. Supervisees who experienced positive supervisory relationships experienced less anxiety and were more willing to self-disclose, which encouraged an atmosphere of learning through interactive feedback (Gunn \& Pistol, 2012). Positive supervisory relationships also create supportive environments where the supervisee is more likely to be receptive to feedback, model supervisor behaviors, communicate their weaknesses, and thus change behaviors that enhance the therapeutic process, motivation, and schema (Borders \& Brown, 2005; Stoltenberg \& McNeil, 2010; Stoltenberg, 1981).

\section{Supervisory Environment}

A supportive environment is essential to promoting counselor identity and skill development. Positive supervisory relationships provide a safe environment, which affects the effectiveness of supervision (Pearson, 2004). Lizzio, Wilson, and Que (2009) investigated psychology supervisees $(N=261)$ and found a significant relationship $(p<.001)$ between supervisee support and perceived effectiveness of supervision. Safe environments that stem from positive supervision relationships encourage supervisees to explore vulnerabilities, experiment, and self-disclose in order to gain self-awareness, understanding, and grow professionally (Gunn \& Pistole, 2012; Pope-Davis \& Coleman, 1997; Worthen \& McNeil, 1996). Worthen and McNeils (1996) qualitative study investigated the supervision 
experiences of $N=8$ (males, $n=4$; female, $n=4$ ) practicum supervisees' from doctoral programs in the Midwest and found that environments that promoted the supervisory relationship through empathy, normalizing, and encouragement were perceived as positive environments. Clear expectations also provide for an inviting environment that encourages openness and disclosure that deepens the relationship, thus the opportunity for learning and growth (Lawton \& Feltham, 2000). As a result, supervisees' develop a greater sense of professional identity, confidence, conceptualization skills, and are more open to change (Gibson, Dollarhide, \& Moss, 2010). Positive environments lead supervisees to be more receptive to feedback and provide an atmosphere for good supervisions and supervisee development (Stoltenberg, 1981; Wiley \& Ray, 1986).

\section{Supervisory Feedback}

Feedback is critical in supporting the development and growth of supervisees' as they develop the awareness needed to advance their cognitive capacity (Falender \& Shafranske, 2004; Lambie \& Sias, 2009; Pope-Davis \& Coleman, 1997). Providing ongoing feedback through the assessment process is imperative to promoting skill refinement (Dryden \& Thorne, 1991). Therefore, supervisors are responsible for providing ongoing, clear, concise, concrete, and constructive feedback during the supervisees training process, which can be integrated through the use of Counselor Competency Scales (Falender \& Shafranske, 2004; Pearson, 2012; Pope-Davis \& Coleman, 1997). Constructive feedback is timely, objective, includes specific statements that are behavior focused rather than character-focused judgments, and identifies supervisees' strengths and areas of growth (Baird, 2005; Falender \& Shafranske, 2004). Interactive feedback influences supervisee skill development, motivation, behavior change, and professional identity, which impacts the supervisees' ability to navigate the therapeutic process effectively (Gibson et al, 2010; Stoltenberg \& McNeil, 2010). Hence, feedback is essential to the supervisees' development and is an element of the DIDSM. 


\section{DIDSM and Supervisee Development}

The DIDSM is an integration of a developmental learning process where cognitive processes and experiences build upon the depth of one's relational experience and the ongoing feedback provided throughout clinical practice. The DIDSM core focus is skill development, identity, professionalism, growth, multicultural competencies, and counseling competencies that align with counseling ethics, laws, and standards (ACA, 2005; Falender \& Shafranske, 2004; Stoltenberg \& McNeil, 2010). Learning and growth takes place in a systematic way where supervisees are challenged to prevent stagnation and explore different perspectives and approaches. As supervisees began to grow and develop, supervisees move from a more global perspective to acquiring depth in knowledge (Stoltenberg \& McNeil, 2010). Supervisees' progression towards knowledge depth is likely to occur when supervisees experience culturally sensitive environments that promote self-awareness through practice and feedback.

The DIDSM incorporates basic counselor skills that lead to therapeutic alliance, case conceptualization, and professionalism (Holloway \& Carroll, 1999). Tenets of the DIDSM enhances the supervision process by creating a structure to assess components necessary for counselor competencies, such as reflection, being present with the client, listening, paraphrasing, and conceptualization of theoretical based decisions, treatment goals, techniques, and professional ethics (Bernard \& Goodyear, 2014; Morrisesette, 2001; Young, 2001). Goal setting and specific developmental areas that need to be addressed to enhance the supervisees' competencies are measured based on their experience and level of placement, which includes standard expectations at each level as supervisees emerge into independent novice professionals (Bernard \& Goodyear, 2014). Therefore, it is important that supervisors provide clear expectations based on the supervisees' developmental level and require supervisees to establish clear written goals (Holloway \& Carroll, 1999; Swank, Lambie, \& Witta, 2012). It is also essential for supervisors to approach supervision from a flexible, but standard model of progression based on the supervisees' developmental level and skill (Blocher, 1983; Borders \& Brown, 2005). 


\section{DIDSM Process}

The DIDSM recognizes the supervisory relationship as the foundation of supervision, thus strategically matches their supervision roles according to the supervisees' developmental level and needs. The primary supervision roles in the DIDSM are teacher, counselor, and consultant. The integration of supervisory roles can address supervisee's developmental level and their needs, while providing the appropriate standard for supervisee evaluation (Bernard \& Goodyear, 2014; Holloway \& Carroll, 1999; Pearson, 2001). The developmental aspect of the DIDSM categorizes supervisees based on three levels of development: beginning Practicum I, intermediate Practicum II, and advanced internship. However, the stages are not always linear and supervisees may revisit previous stages during certain situations and servicing of diverse clients (Lawton \& Feltham, 2000; Stoltenberg \& Delworth, 1987; Stoltenberg \& McNeil, 2010; Haber, 1996). For instance, regardless of supervisee level, supervisees prefer high structure when working with clients with critical issues, such as suicide (Ladany et al., 2001; Pearson, 2001).

Level I, beginning supervisees are more imitative, impressionable, dependent, highly motivated, and are likely to experience higher levels of anxiety than supervisees in later stages (Ronnestad \& Skovholt, 2003; Young, 2001). Therefore, supervisors are encouraged to support supervisees by normalizing anxiety related feelings of operating out of their comfort zone and trying new interventions, which is important when applying the DIDSM with beginner supervisees (Lambie \& Sias, 2009; Pearson, 2004). To help supervisees experience less anxiety it is beneficial to create a structured environment where supervisees know what to expect, while maintaining a sense of flexibility to modify supervision sessions when appropriate (Pearson, 2004). As supervisees transition from the beginning stage, they begin to develop a higher level of autonomy, empathy, self-awareness, awareness of others, professional identity as a counselor, and are more client focused (Ronnestad \& Skovholt, 2003; Stoltenberg \& Delworth, 1987). In this case, DIDSM supervisors relinquish structure and modify roles in order to assist supervisee development. Supervisors provide less structure as supervisees navigate from beginner supervisees to 
advanced supervisees (Stoltenberg, 2005). The DIDSM model helps structure supervision by creating an agenda that aligns with opportunities to operate from different supervision roles throughout the session, while intentionally structuring supervision to align with supervisees' level of development.

\section{DIDSM Levels}

Beginning Level I supervisees seek more direction and rely on specific interventions. At this level, it is important for supervisors to operate from their teacher role by providing direct structure, encouragement, and hands on interventions, such as techniques, role-playing, and brainstorming (Pope-Davis \& Coleman, 1997). According to Baird (2005), a didactic approach that provides structure and a direct teacher method can be used to decrease supervisees' anxiety. Supervisees may benefit from specific examples of what is expected, such as an example of clinical case notes. Level I students can also benefit from supervisors operating from a counselor role where they model behaviors expected of the supervisee and help supervisees process their experiences, which can help reduce supervisee anxiety (Pearson, 2004). At level two, supervisors primarily operate from the role of a counselor because intermediate supervisees are more comfortable and confident due to practicing counseling techniques and foundational principles. Supervisors promote the supervisee growth and self-awareness through an individualized person-centered approach that helps the supervisee recognize possible issues of transference and countertransference (Stoltenberg, 1981). The supervisor takes on the role as a consultant and colleague when working with advanced supervisees, encouraging supervisees' autonomy, independence, responsibility, and theoretical brainstorming (Haber, 1996; Lambie \& Sias, 2009; Ronnestad \& Skovholt, 2003). Advanced supervisees are in the last stage (Level 3), the last transition prior to them becoming independent practitioners who may not have supervision throughout their counseling career (Bernard \& Goodyear, 2014). 
The DIDSM focuses on the supervisees' training based on the interventions used and the supervision processes needed to enhance the communication process of counseling, which helps with conceptualization and personalization skills as the counselor develops. Supervisors heighten the use of interventions, such as self-reflection and confrontation. Interventions help challenge intermediate and advanced supervisees move beyond their safety zone, extend their worldview, as well as focus on analysis, emotional responses, and plausible issues of transference and countertransference (Stoltenberg, 2005). The developmental process of the DIDSM provides a structured system that promotes supervisee growth, ethical practice, and multicultural sensitivity.

\section{DIDSM Strengths and Areas of Improvement}

The DIDSM is based on supervision models that involve developmentally training supervisees while providing flexibility in the supervisory role. It addresses supervisory roles (i.e., counselor, consultant, teacher) and allows for interpersonal process recall, case report, observation, and recording. Although developmental models, such as the IDM are researched and the integrated developmental model of the DIDSM is researched based, there is a lack of research on the DM. The DIDSM has been implemented by supervisors based on the components of this model incorporating research based supervision models. However, to strengthen the awareness of the DIDSM model and evidence based supports, additional research pertaining to the evaluation of client satisfaction and outcomes could be implemented.

\section{Evaluation and Assessment}

Supervisees are encouraged to grow and understand their responsibilities as supervisees transitioning into the profession when they solicit input from supervisors and when supervisors provide ongoing assessments that encourage supervisees to reflect on their progress (Pearson, 2004; Tyson, Culbreth, \& Harington, 2008). A strength of the DIDSM is that it includes formative and summative evaluations, which are critical to the supervision 
process (see Appendix A to view a copy the supervision goals and ccs-r reflection guide). The DIDSM provides ongoing assessment, evaluation, monitoring, as well as other core components (i.e., relationship base, skill acquisition) of supervision key to the supervision process (Swank \& Lambie, 2011). The DIDSM utilizes the CCS, which is a scale that can be used to encourage self-reflection, independent monitoring, and personal ownership of ones' progress (Swank et al, 2012). The DIDSM also uses the CCS as a standard measure to clarify expectations and evaluate competencies, which can help supervisees self-reflect, self-monitor, and gain awareness about their skill levels (Ladany et al, 2001).

Implementing the CCS through the lens of the DIDSM can decrease anxiety and increase supervisees' awareness and autonomy. Throughout the semester, students are responsible for reviewing their counseling sessions, tracking their progress, and evaluating themselves by indicating specific examples and the times they demonstrated specific skills on the CCS. Supervisees can also benefit from hearing and discussing specific instances where they demonstrated counseling skills. It is can also be beneficial for supervisees to reflect upon times they may have missed an opportunity to use a skill.

\section{Multiculturalism}

The DIDSM incorporates cross-cultural facets by encouraging reflection through self-evaluation and recommends interpersonal process recall (IPR) through video-recorded client sessions, while exposing supervisees to video simulations and role-plays of responding to cultural differences (Bernard \& Goodyear, 1992). These methods encourage the development of the supervisee to become independent reflective practitioners (Morrissette, 2001; Pope-Davis \& Coleman, 1997). The DIDSM tenets support supervisory professionalism, ethics, and supervisee growth; while there are challenges that supervisors may face when using the DIDSM.

\section{Individuality}


The person-centered approach to the DIDSM is beneficial to the supervisory relationship because it engenders key elements of relationship building, such as empathy, warmth, respect, trust, and genuineness and is likely to be modeled by the supervisee in the parallel process of building the therapeutic alliance with clients (Bernard \& Goodyear, 2014; Estraada, 2005; Studer, 2006; Stoltenberg \& McNeil, 2010; Young, 2001). The personcentered approach can also promote cultural sensitivity.

\section{Potential Challenges}

Supervisors using the DIDSM may encounter challenges common to interpersonal interactions, counseling, and supervision. Although common relationship challenges may present themselves during the supervisory process, challenges can also be used to advance the supervisees' development, awareness of counseling, and skill. Foreseen challenges may consist of transference, countertransference, the limitation of supervisees' overgeneralizing, and supervisors' incorrectly categorizing supervisees' level, which can lead to not meeting the supervisee where they are in order to provide what is needed for them to learn and grow (Pope-Davis \& Coleman, 1997). The DIDSM can mitigate common supervision challenges through its person-centered approach and evaluation process that includes the comparison of supervisee's self-evaluations with the supervisors' evaluations.

\section{Countertransference}

Countertransference occurs when a supervisees previous experiences affects how they interact with clients (Tyson et al, 2008). While countertransference is a common challenge in counseling, the likelihood of countertransference is decreased with the DIDSM process of genuineness, reflection, as well as the analysis of counselor reflective response, feeling, and behavior (Bernard \& Goodyear, 2014; (Dryden \& Thorne, 1991; Morrisesette, 2001). Additionally, the Discrimination component of the DIDSM can help supervisees gain awareness when supervisors use the counselor supervision role to help supervisees' process information. The DIDSM's Discrimination component helps supervisees identify client 
issues that may trigger the supervisee's emotions, responses, and/or interactions with clients. The aforementioned can lead supervisors to refer supervisees to seek counseling if necessary, as well as check in and monitor supervisees regarding their efforts to address personal challenges that were interfering with counseling sessions (Tyson et al, 2008).

\section{Dual Relationships}

Dual relationships can potentially be problematic. However, the DIDSM's use of congruence, awareness, supervision, and role responsibilities to focus on modeling ethical behavior can mitigate potential issues. Supervisors can model expected behaviors by selfreflecting and by engaging in mentor consultations (ACA, 2005, ACA 2014).

\section{Multiculturalism}

Cultural insensitivity can be problematic in counseling. Language and ethnic differences have been interpreted as deficits where minorities have been categorized as inferior and in a negative manner (Pope-Davis \& Coleman, 1997; Sue, Carter, Casas, Fouad, Ivey, Jensen, LaFromboise, Manese, Ponterotto, \& Zazquez-Nutall, 1998). Multicultural challenges can be addressed by being empathetic, genuine, culturally sensitive and building a relationship of acceptance and understanding. For instance, if working with a supervisee whose native language is not English, the supervisor can be patient, speak clearly, use written communication, translate information into their native language, check for understanding, and disregard making assumptions (Pederson, 1988). Multicultural competencies can be strengthened through professional development, consultation, cultural readings and pedagogy, feedback, diverse experiences, and by implementing goals of being nonjudgmental when working with individuals whose culture (i.e., nonverbal behaviors, mannerisms, language) may differ from the supervisees' culture.

It is important that supervisors and supervisees do not misjudge minorities as resistant, unconfident, non-assertive, or unmotivated because they may use less eye contact, 
approach issues differently, and may display mannerisms that differ from Americas dominant culture, communication, and interpretation of behaviors (Baird, 2005; Pope-Davis \& Coleman, 1997). In fact, the DIDSM encourages supervisors to acknowledge, accept, embrace, and respect difference in the light of diversity, while avoiding overgeneralizations, stereotypes, assumptions, and limitations that fail to view circumstances conceptually and from different perspectives (Estraada, 2005; Haber, 1996; McGrath \& Axelson, 1999; Pope-Davis \& Coleman, 1997; Sue \& Sue, 1990). The cognitive developmental basis of the DIDSM considers the sociocultural aspects of the supervisee. Awareness of cultures is foundational to multiculturalism, however in isolation; it could lead to generalizations about the client that counteract with DIDSM's client centered approach. In addition to the client centered approach toward the supervisee, the interpersonal foundation of relationship building in DIDSM provides an atmosphere that encourages supervisees to express their multicultural needs. The DIDSM normalizes supervisees' discussion of their strengths and areas of improvement to promote growth and reduce anxiety (Bernard \& Goodyear, 2014).

The DIDSM focuses on supervisees as an individual, recognizing assimilation, experiences, and individual perception can differ (Pope-Davis \& Coleman, 1997). Therefore, the person is the foundation and primary source for understanding and can provide information about their worldview, values, and culture. The aforementioned may help supervisees consider cultural amalgamation and negate conceptualizing individuals in a negative, hopeless, restrictive, stereotypical deficit scope, which neglects a social justice approach that perpetuates experiences and feelings of marginalization and powerlessness (Estraada, 2005; Nugent, 1994).

\section{DIDSM Supervision Goals}

The DIDSM model helps with the evolving process of supervision. Supervisees are encouraged to identify goals and reflect on their practice. Supervisee goals may include professional awareness, case-conceptualization, self-awareness, and supervision skills. The 
following can help supervisees successfully meet their goals: (a) having written concrete goals, (b) providing weekly updates and reflecting upon the progress made toward their goals, (c) supervision of supervision discussions pertaining to their goals and how supervision activities connect to the supervisee's development, (d) and intentionally deciding to work toward goals through a devised plan (i.e., timeline, concrete behaviors) for meeting expected goals. For instance, professional awareness may be obtained by engaging in professional experiences, such as conferences, reading, and consultations with supervisors and peers. Whereas, case-conceptualization (CC) may be strengthened by learning about theoretical orientations and implementing DIDSM tenets. Supervisees can review and provide counseling resources (i.e., articles on theoretical orientations), ask about their students (triadic supervisees) theoretical orientations, and have conversations about how their students conceptualized clients and incorporated CC information into sessions and counseling case notes.

\section{Summary}

Counselor supervision is important to promote counselor development and client safety. Supervision is a monitoring and training process that focuses on counselor development, skill, and competencies in order to promote ethical counseling services. Therefore, the purpose of this paper was to discuss the importance and ethical responsibilities of supervisors, the benefits of supervision, as well as present the Discrimination Integrated Developmental Supervision Model (DIDSM), which is an integration of Bernard's (1997) Discrimination process model and Stoltenberg and Delworth's (1987) Integrated Developmental Model. The following DIDSM tenets have been found to be essential to counselor supervision: (a) the supervisory relationship, (b) modeling, (c) feedback, and (d) the awareness of self and others. Additional components addressed in the manuscript included information about how the DIDSM can address challenges, the supervision process, evaluation, multiculturalism in supervision, as well as how professional experiences and supervision goals could be met through the use of the DIDSM. The aforementioned experiences can 
help supervisees to understand and practice being intentional, transparent, as well as the need to initiate clear expectations, conversations, deadlines, and request supervisee information prior to supervision. Additional implications consists of furthering the research on client outcomes from supervisees trained under DIDSM which could advance therapeutic outcomes and consistent evaluative supervision across practices that is culturally sensitive to the needs of diverse supervisees. Research can explore the impact DIDSM may have on supervisee and supervisors' cultural sensitivity and multicultural competencies. Further research on the DIDSM is important because it may help support the progression of diverse supervisors and promote culturally sensitive supervision and counseling practices.

The DIDSM foresees supervision as ongoing professional development. Therefore, the DIDSM's components can serve supervisors and counselors in the profession to self-monitor and develop accountability partners, which could benefit all counselors, including professional school counselors.

\section{MODELO DE SUPERVISÃO DO DESENVOLVIMENTO INTEGRADO DE DISCRIMINAÇÃO}

RESUMO: A supervisão do conselheiro é importante para o desenvolvimento de futuros conselheiros e para a segurança do cliente. A supervisão é um processo que fornece monitoramento, treinamento, consulta e feedback para ajudar no desenvolvimento, nas habilidades e nas competências dos conselheiros. Portanto, o objetivo deste manuscrito é apresentar o Modelo de Supervisão do Desenvolvimento Integrado de Discriminação (DIDSM), que é uma integração do modelo de processo Discriminação de Bernard (1997) e do Modelo Integrado de Desenvolvimento de Stoltenberg e Delworth (1987). O autor também discutirá como os seguintes princípios da DIDSM são essenciais para a supervisão do conselheiro: (a) a relação de supervisão, (b) modelagem, (c) feedback e (d) a consciência de si e dos outros.

PALAVRAS-CHAVE: Supervisão de conselheiro; Modelo de desenvolvimento integrado de discriminação; Relação de supervitoria

\section{REFERENCES}

American Counseling Association. ACA code of ethics. Alexandria: Virginia, 2014.

American Counseling Association. ACA code of ethics. Alexandria: Virginia, 2005. 
BAIRD, Brian. The internship, practicum, and field placement handbook: A guide for helping professions (4th ed.). Upper Saddle River: New Jersey, 2005.

BERNARD, Janine, \& GOODYEAR, Rodney. Fundamentals of clinical supervision (5 $5^{\text {th }}$ ed.). Boston: Massachusetts, 2014.

BERNARD, Janine. Supervision training: A discrimination model. Counselor Education and Supervision, 19(1), 60-68. 1979.

BLOCHER, Donald. Toward a cognitive developmental approach to counseling. The Counseling Psychologist, 11(1), 27-34. 1983

BORDERS, L. Dianne, \& BROWN, Lori. The new handbook of counseling supervision. Alexandria: Virginia, 2005.

COREY, Gerald, COREY, Marianne, \& CALLANAN, Patrick. Issues and ethics in the helping professions ( ${ }^{\text {th }}$ ed.). Pacific Grove: California, 2011.

DRYDEN, Windy, \& THORNE, Brian. Training and supervision for counseling in action. Newbury Park: California, 1991.

ESTRADA, Diane. Multicultural conversations in supervision: The impact of the supervisor's racial/ethnic background. Guidance and Counseling, 21(1), 14-20, 2005.

FALENDER, Carol, \& SHAFRANSKE, Edward. Clinical supervision: A competency-based approach. Washington: D.C., 2004.

GIBSON, Donna, DOLLARHIDE, Colette, \& MOSS, Julie. Professional identity development: A grounded theory of transformational tasks of new counselors. Counselor Education \& Supervision, 50, 21-38. 2010.

GOODYEAR, Rodney, \& BERNARD, Janine. Clinical supervision: Lessons from the literature. Counselor Education and Supervision, 38, 6-23. 1998.

GUNN, Joshua, \& PISTOLE, M. Carole. Trainee supervisor attachment: Explaining the alliance and disclosure in supervision. Training and Education in Professional Psychology, 6(4), 229-237. 2012.

HABER, Russell. Dimensions of psychotherapy supervisions: Maps and means. New York: New York, 1996.

HERLIHY, Barbara., \& COREY, Gerald. ACA etbical standards casebook (7th ed.). Alexandria: Virginia, 2015.

HOLLOWAY, Elizabeth, \& CARROLL, Michael. Training counselling supervisors. Thousand Oaks: California, 1999. 
KOLTZ, Rebecca, ODEGARD, Melissa, FEIT, Stephen, PROVOST, Kent, \& SMITH, Travis. Parallel process and isomorphism a model for decision making in the supervisory triad. The Family Journal, 20(3), 233-238. 2012.

LADANY, Nicholas, MAROTTA, Sylvia, \& MUSE-BURKE, Janet. Counselor experience related to complexity of case conceptualization and supervision preference. Counselor Education and Supervision, 40(3), 203-219. 2001.

LAMBIE, Glenn, \& SIAS, Shari. An integrative psychological developmental model of supervision for professional school counselors-in-training. Journal of Counseling and Development, 87, 349-356. 2009.

LAMBIA, Glenn, SMITH, Heather, \& IEVA, Kara. Graduate counseling students' levels of ego development, wellness, and psychological disturbance: An exploratory investigation. The Adultspan Journal, 8(2), 114-127. 2009.

LAWTON, Barbara, \& FELTHAM, Colin. Taking supervision forward: Enquiries and trends in counselling and psychotherapy. Thousand Oaks: California, 2000.

LEACH, Mark, STOLTENBERG, Cal, EICHENFIELD, Gregg, \& MCNEILL, Brian. Self-Efficacy and Counselor Development: Testing the Integrated Developmental Model. Counselor Education and Supervision, 37(2), 115-24. 1997.

LIZZIO, Alf, WILSON, Keithia, \& QUE, Janelle. Relationship dimensions in the professional supervision of psychology graduates: Supervisee perceptions of processes and outcome. Studies in Continuing Education, 31(2), 127-140. 2009.

MCAULIFFE, Garrett, \& ERIKSEN, Karen. Teaching strategies for constructivist and developmental counselor education. Westport: Connecticut, 2002.

MCGRATH, Patrick, \& AXELSON, John. Accessing awareness and developing knowledge. Foundations for skill in a multicultural society. (3 ${ }^{\text {rd }}$ ed.). Pacific Grove: California, 1999.

MORRISSETTE, Patrick. Self-supervision: A primer for counselors and belping professionals. Lillington: North Carolina, 2001.

MURPHY, Sally, \& KAFFENBERGER, C. ASCA national model: The foundation for supervision of practicum and internship students. Professional School Counseling, 10(3), 289296. 2007.

NORCROSS, John. Psychotherapy relationships that work: Evidence-based responsiveness. New York: New York, 2011.

PEARSON, Quinn. A case in clinical supervision: A framework for putting theory into practice. Journal of Mental Health Counseling, 23(2), 174-183. 2001.

PEARSON, Quinn. Getting the most out of clinical supervision: Strategies for mental health. Journal of Mental Health Counseling, 26(4), 361-373. 2004. 
PEDERSEN, Paul. A handbook for developing multicultural awareness. Alexandria: Virginia, 1988.

POPE-DAVIS, Donald, \& COLEMAN, Hardin. Multicultural counseling competencies: Assessment, education, and training, and supervision. Thousand Oakes: California, 1997.

RAPISARDA, Clarrice, \& BRITTON, Paula. Sanctioned supervision: Voices from the experts. Journal of Mental Health Counseling, 29(1), 81-92. 2007.

RONNESTAD, Michael, \& SKOVHOLT, Thomas. The journey of the counselor and therapist: Research findings and perspectives on professional development. Journal of Career Development, 30(1), 5-44. 2003.

STOLTENBERG, Cal. Approaching supervision from a developmental perspective: The counselor complexity model. Journal of Counseling Psychology, 28(1), 59-65. 1981.

STOLTENBERG, Cal. Enhancing professional competence through developmental approaches to supervision. American Psychologist, 60(8), 857-864. 2005.

STOLTENBERG, Cal \& DELWOTH, Ursula. Supervising counselors and therapists. San Francisco: California, 1987.

STOLTENBERG, Cal, \& MCNEILL, Brian. IDM supervision: An integrative supervision model for supervising counselors and therapist (3rd ed.). New York: New York, 2010.

STUDER, Jeannine. Erik Erikson’s psychosocial stages applied to supervision. Guidance \& Counseling, 21, 168-173. 2006.

SUE, Derald, CARTER, Robert, CASAS, J. Manuel, FOUAD, Nadya, IVEY, Allen, JENSEN, Margaret, LAFROMBOISE, Teresa, MANESE, Jeanne, PONTEROTTO, Joseph, \&VAZQYEZ-NUTALL, Ena. Multicultural counseling competencies: Individual and organizational development. Thousand Oaks: California, 1998.

SWANK, Jacqueline, LAMBIE, Glenn, \& WITTA, E. Lea. An exploratory investigation of the counseling competencies scale: A measure of counseling skills, dispositions, and behaviors. Counselor Education \& Supervision, 51, 189-205. 2012.

TYSON, Lawrence, CULBRETH, John, \& HARRINGTON, Judith. Critical incidents in clinical supervision: Addictions, community, and school counseling. Alexandria: Virginia, 2008.

WHEELER, Sue. Training counsellors: The assessment of competence. New York: New York, 1996.

WILEY, Mary, \& RAY, Philip. Counseling supervision by developmental level. Journal of Counseling Psychology, 33, 439-455. 1986.

WORTHEN, Vaughn, \& MCNEILL, Brian. A phenomenological investigation of "good" supervision events. Journal of Counseling Psychology, 43(1), 25-24. 1996. 
YOUNG, Mark. Learning the art of helping: Building blocks and techniques (2nd ed.). Upper Saddle River: New Jersey, 2001.

Recebido em: 28/04/2018.

Aprovado em: 01/06/2018. 


\section{Appendix A}

Supervision Goals and CCS-R Reflection Guide

Name:

Date

Strong: The emerging counselor

Demonstrates Strong Competency at the Graduate Level

Satisfactory: Demonstrates Primary Competency at the Graduate Level

Weak/Limited: Does Not Demonstrate Primary Competency at the Graduate Level

\begin{tabular}{|c|c|c|c|c|}
\hline Area/Competency & Excellent & Satisfactory & Limited & Score \\
\hline $\begin{array}{l}\text { APA Style - } \\
\text { Appropriately used APA 6th edition } \\
\text { throughout the paper (i.e. title page, } \\
\text { headings). The paper was well written } \\
\text { and flowed. Citations and references } \\
\text { were used as needed. }\end{array}$ & & & & \\
\hline $\begin{array}{l}\text { Theory - } \\
\text { The emerging counselor demonstrated } \\
\text { knowledge of their theoretical orienta- } \\
\text { tion, the importance of theory for be- } \\
\text { ginning counselors, and discussed how } \\
\text { they may utilize their theoretical orien- } \\
\text { tation to help with their counseling } \\
\text { skills and/or development. }\end{array}$ & & & & \\
\hline $\begin{array}{l}\text { Counseling Skills - } \\
\text { The emerging counselor demonstrated } \\
\text { awareness and ability to reflect on their } \\
\text { counseling skill development (i.e., } \\
\text { emerging counselor provided 1-2 ex- } \\
\text { amples and/or a description of how } \\
\text { they assessed their development). The } \\
\text { emerging counselor discussed their } \\
\text { counseling strengths and areas of im- } \\
\text { provement. The emerging counselor } \\
\text { provided a narrative account of the } \\
\text { specific learning objectives for their } \\
\text { specialty area (e.g., school counseling, }\end{array}$ & & & & \\
\hline
\end{tabular}




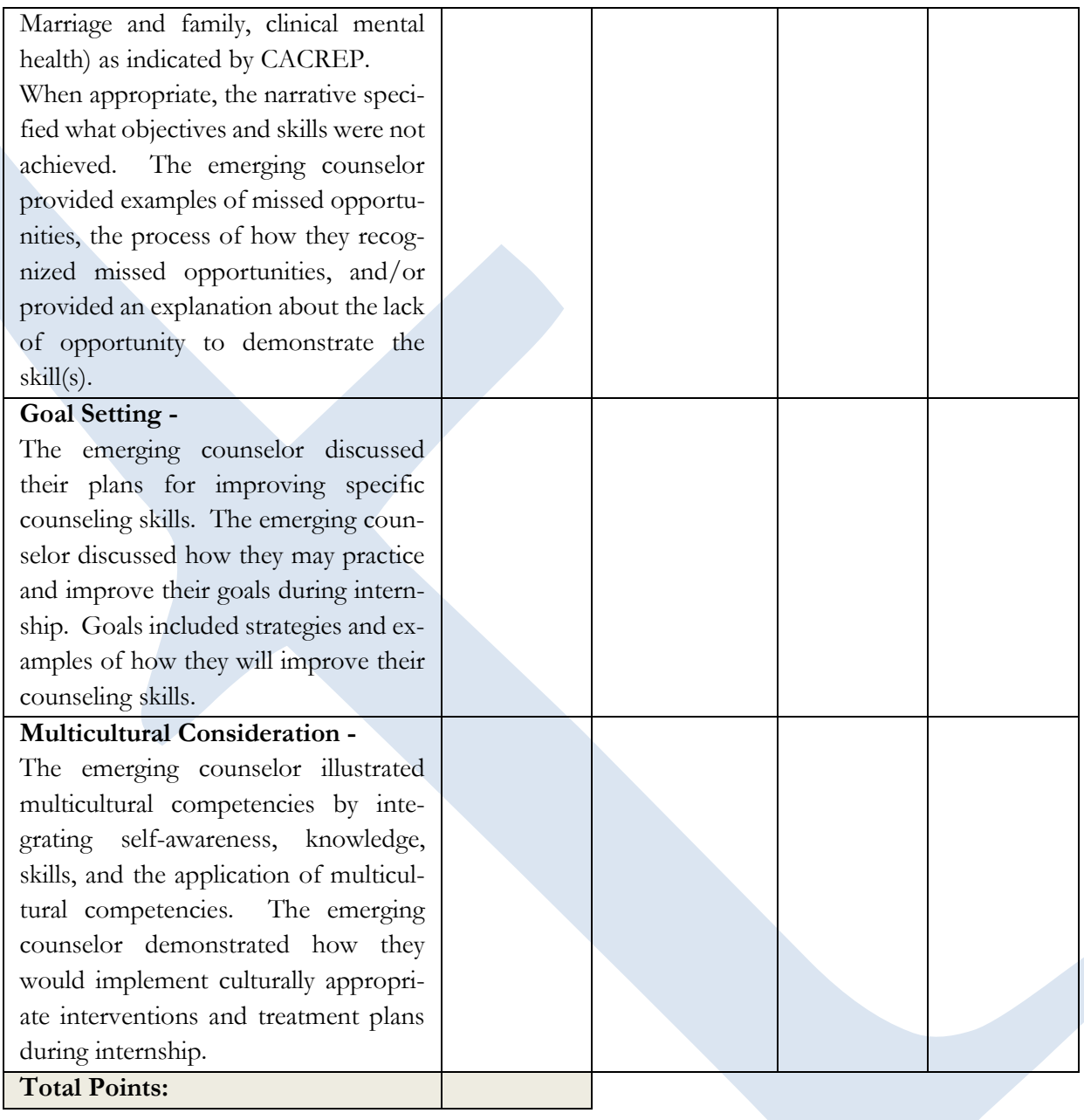

